\title{
1 Chemical defense acquired via pharmacophagy can lead to herd protection in
}

2 a sawfly

3

$4 \quad$ Pragya Singh ${ }^{1, *}$, Neil Grone ${ }^{1}$, Lisa Johanna Tewes ${ }^{1}$ and Caroline Müller ${ }^{1}$

$5 \quad{ }^{1}$ Chemical Ecology, Bielefeld University, Universitätsstr. 25, 33615 Bielefeld, Germany

6

$7 \quad *$ Corresponding Author:

$8 \quad$ Email: pragya.singh42019@gmail.com

9 ORCiD: https://orcid.org/0000-0002-7411-3206

\section{Author Contributions}

12 Conceptualization and funding acquisition: CM; methods development/experimental design:

PS, CM; data collection: experiment 1 and 2: NG, PS, experiment 3: PS, chemical analysis:

PS, LJT; data validation and analysis: PS; data visualization: PS; experiment illustrations:

NG; writing original draft: PS, CM.

\section{Acknowledgements}




\section{Abstract}

Predation is an important selection pressure acting on organisms, with organisms evolving diverse anti-predator strategies to combat it. One such widespread strategy is chemical defense in which organisms either synthesize or extrinsically acquire defensive chemicals. Little is known about the intraspecific transfer of such chemicals and if such chemicals acquired from conspecifics can also serve as defense against predation. Here, we used adults of the turnip sawfly, Athalia rosae, which can acquire neo-clerodane diterpenoids ('clerodanoids') via pharmacophagy after exposure to the plant, Ajuga reptans. We show that clerodanoid access mediates protection against predation by mantids for the sawflies, both in a no-choice feeding assay and a microcosm setup. Moreover, even indirect access to clerodanoids, via nibbling on conspecifics that had access to the plant, resulted in protection against predation albeit to a much lower degree than direct access. Furthermore, sawflies that had no direct access to clerodanoids were less consumed by mantids when they were grouped with conspecifics that had direct access. Most, but not all, of such initially undefended sawflies could acquire clerodanoids from conspecifics that had direct access to the plant, although in low quantities. Together our results demonstrate that clerodanoids serve as chemical defense that can be intraspecifically transferred. Moreover, the presence of chemically defended individuals in a group can confer protection onto conspecifics that had no direct access to clerodanoids, suggesting a 'herd-protection' effect.

\section{Keywords}

Sequestration, pharmacophagy, automimicry, plant-insect interaction, phytochemicals, Hierodula patellifera (Mantidae), Hymenoptera 
46

47

48

49

\section{Introduction}

Predation is an important biotic factor that many organisms in the wild encounter. To defend themselves, organisms exhibit a wide diversity of anti-predator strategies (Edmunds, 1974; Eisner et al., 2005; Bergen \& Beldade, 2019; Rowland et al., 2020). Chemical defense is one such anti-predator strategy that is widespread amongst organisms, ranging from microorganisms (Matz et al., 2008) to multicellular organisms (Santos et al., 2016; Pančić \& Kiørboe, 2018; Sugiura, 2020). Such defensive chemicals can either be synthesized de-novo or acquired extrinsically, for example, from the host plant diet (Opitz \& Müller, 2009; Erb \& Robert, 2016; de Castro et al., 2021). For example, the oleander aphid, Aphis nerii, sequesters cardenolides from its host plant species, and utilizes these defensive compounds against both vertebrate and invertebrate predators (Züst et al., 2018). Alternatively, organisms can specifically take up defensive chemicals independently of nutritional requirements, e.g. via pharmacophagy (Boppré, 1984; Nishida, 2014; Paul et al., 2021b). For example, adults of some danaine butterfly species actively incorporate defensive chemicals like pyrrolizidine alkaloids from sources such as dried plant parts (Lawson et al., 2021; Tea et al., 2021). While these acquired chemicals confer protection on the individual taking them up, it is less wellelucidated whether and how this protection can extend to conspecifics that may not have access to these chemicals directly from the source.

The possibility that chemically defended individuals confer protection from predation on initially undefended conspecifics, what we coin as 'herd-protection', could be realized via different means. For example, individuals could acquire such chemicals not only directly from the (plant) source but also indirectly via intraspecific (Lawson et al., 2021; Paul et al., 2021a) or interspecific (Hashimoto \& Hayashi, 2014; Tea et al., 2021) interactions. Such indirectly acquired chemicals could then be used in the context of defense against predation.

Alternatively, after attacking a chemically defended individual, a predator may be deterred 
71 from attacking even chemically undefended conspecifics if it associates the phenotype with

72 chemical defense by learned aversion or avoidance (Berenbaum \& Miliczky, 1984;

73 Hämäläinen et al., 2020; Tuttle et al., 2021). This phenomenon is often seen in combination

74

with automimicry, wherein undefended individuals (mimics) benefit from the unpalatability of defended individuals (models) (Brower et al., 1970; Aubier et al., 2017). Furthermore, unpalatability or unprofitability of organisms is often associated with bright or aposematic coloration that functions as warning signal to predators (Cyriac \& Kodandaramaiah, 2019; Kikuchi et al., 2021). There is usually positive density-dependence in aposematism, such that conspicuous warning signals are more effective when they are common (Chouteau et al., 2016; Kikuchi et al., 2021).

Understanding how the presence of chemically defended individuals affects the rest of the population is an important question as studies have shown that there can be intraspecific variation in chemical defense, with some individuals lacking chemical defenses entirely (Best et al., 2018; Prudic et al., 2019; Sculfort et al., 2020; Mattila et al., 2021). Such variation could arise if the defensive chemicals have an associated cost, for example, for acquisition and/or maintenance of the chemical defense (Dimarco \& Fordyce, 2017). Variation may also be influenced by intrinsic factors such as the age, sex, reproductive phase or immunological status of the individuals (Smilanich et al., 2009; Zvereva \& Kozlov, 2015; Arias et al., 2016). In such scenarios with intraspecific variation in chemical defense, the degree of protection from predation for chemically undefended individuals depends on the frequency of defended and non-defended individuals (Gamberale-Stille \& Guilford, 2004; Finkbeiner et al., 2018). At higher density of chemically defended individuals, the motivation of predators could be reduced to search for undefended prey (Skelhorn et al., 2011), it may be harder to detect undefended prey (Gamberale-Stille \& Guilford, 2004; Skelhorn et al., 2011), or more undefended individuals could indirectly access the chemicals and gain protection. 
An excellent model system for examining the effect of defensive chemicals in deterring predation both directly and indirectly is the turnip sawfly, Athalia rosae (Hymenoptera: Tenthredinidae). The larvae of this species are well-studied for sequestering metabolites, i.e. glucosinolates, of their Brassicaceae host plants, which act as defense against various invertebrate and vertebrate predators (Müller \& Brakefield, 2003; Müller \& Arand, 2007; Opitz et al., 2010; Matsubara \& Sugiura, 2017). The bright orange adults still contain glucosinolates sequestered by the larvae (Müller \& Sieling, 2006) but do not seem to be protected by these compounds against predators such as birds and lizards (Vlieger et al., 2004; Boevé \& Müller, 2005). However, A. rosae adults can additionally acquire other specialized metabolites, neo-clerodane diterpenoids (potentially together with other compounds, hereafter called clerodanoids), by pharmacophagy from certain plant species, such as Ajuga reptans or Clerodendrum trichotomum (both Lamiaceae) (Kawai et al., 1998). Some of the clerodanoids found in insect bodies are likely slightly modified metabolic products from plant derived clerodanoids (Amano et al., 1999; Paul et al., 2021a). Moreover, these compounds can be acquired indirectly by nibbling on conspecifics that were exposed to plant material (Paul et al., 2021a). While effects of clerodanoids on mating behavior have been shown previously (Amano et al., 1999; Paul \& Müller, 2021), empirical evidence for other functions such as in defense against predation is scarce and indirect (Nishida \& Fukami, 1990). In the laboratory, the cultures are usually maintained without $A$. reptans leaves, suggesting that clerodanoid access is not essential for the sawflies' survival (Paul et al., 2021b, 2021a; Paul \& Müller, 2021). Moreover, there is evidence for associated costs of clerodanoid uptake in $A$. rosae, such that adults with clerodanoid access exhibit a reduced lifespan (Zanchi et al., 2021). Thus, most likely there is intraspecific variation in clerodanoid status by $A$. rosae in the wild. 
120 We aimed to study whether uptake of clerodanoids can function as defense against predation

121 both for focal individuals that directly acquire these compounds after access to plants, and

122 indirectly for other conspecifics that come into contact with the focal individuals. Therefore,

123 we observed the response of mantid predators in no-choice feeding assays to sawflies that

124 either had access to clerodanoids directly from plants or indirectly from conspecifics or had

125 no access (experiment 1). Next, we investigated survivorship of sawflies with or without

126 clerodanoid access in both presence and absence of a predator (experiment 2). Lastly, we

127 investigated if the presence of sawflies with clerodanoid access conferred protection from

128 predation on conspecifics with no clerodanoid access and if this varied with their relative

129 abundance (experiment 3). We also investigated the clerodanoid acquisition of sawflies from

130 different treatments using chemical analysis (experiment 3). We predicted that both direct and

131 indirect clerodanoid acquisition should lead to protection from predation by the mantids.

132 Furthermore, presence of chemically defended sawflies should confer protection from

133 predation on conspecifics, with protection increasing with proportion of chemically defended

134 individuals in the group. We also expect sawflies without clerodanoid access that were

135 grouped with conspecifics with clerodanoid access to acquire clerodanoids.

\section{Materials and Methods}

\section{(a) Experimental animals}

The individuals of $A$. rosae used in this experiment were taken from a laboratory culture established using adults collected in the surroundings of Bielefeld, Germany, and supplemented annually with field-caught insects. The culture was maintained in mesh cages

$142(60 \times 60 \times 60 \mathrm{~cm})$ with overhead lighting in a laboratory at room temperature with a $16 \mathrm{~h}: 8 \mathrm{~h}$ 
and provided with Sinapis alba (Brassicaceae) plants for the females to oviposit. Emerging larvae were raised on Brassica rapa var. pekinensis (Brassicaceae) plants. Males and females were collected and separated within two days of pupal eclosion. Adults were kept in a climate chamber at $20{ }^{\circ} \mathrm{C}(16 \mathrm{~h}: 8 \mathrm{~h}$ light: dark cycle, $70 \%$ relative humidity) before being used in experiment 1 and 2, and were kept in the laboratory under culture conditions for experiment 3. All adults were fed a maintenance diet of a honey-water mixture (1:50 dilution). Adults were allocated randomly to the different treatments of no clerodanoid access $(\mathrm{C}-)$, direct clerodanoid access $(\mathrm{C}+)$ or indirect clerodanoid access $(\mathrm{AC}+)$. For the $\mathrm{C}+$ treatment, adults got access to a leaf section $\left(0.8 \mathrm{~cm}^{2}\right)$ of $A$. reptans for 48 hours, while for C- no A. reptans leaf was provided. For the $\mathrm{AC}+$ treatment, adults got access to a $\mathrm{C}+$ conspecific of the same sex (prepared as above) for 48 hours. $S$. alba plants were grown from seeds in a climate chamber $\left(20^{\circ} \mathrm{C}, 16 \mathrm{~h}: 8 \mathrm{~h}\right.$ light: dark, $70 \%$ r.h. $)$, while $B$. rapa and $A$. reptans plants were grown from seeds in a greenhouse $\left(\geq 20^{\circ} \mathrm{C}, 16 \mathrm{~h}: 8 \mathrm{~h}\right.$ light: dark, $70 \%$ r.h.).

Twenty-three sixth instar individuals of Hierodula patellifera (Mantidae) were purchased (www.interaquaristik.de) and reared in individual cages $(20 \mathrm{~cm} \times 20 \mathrm{~cm} \times 20 \mathrm{~cm})$ on a diet of crickets in a climatized room $\left(\sim 20^{\circ} \mathrm{C}\right)$ on a diet of crickets. The mantids used in the experiment were not exposed to the sawflies before experiment 1, and were starved 48 hours before experiment 1. Each mantid was offered a cricket before experiment 2 and 3 to avoid starvation effects over the experimental days, and those individuals that did not consume the cricket were excluded as mantids usually stop eating when nearing a molt.

\section{(b) Experiment 1: No-choice feeding assay to examine effect of clerodanoid access on}

\section{predator deterrence}

Mantids were placed individually in transparent containers $(9.5 \mathrm{~cm}$ diameter, $20 \mathrm{~cm}$ height), one $\mathrm{C}-, \mathrm{C}+$ or $\mathrm{AC}+$ female sawfly was introduced in the container (figure $1 a$ ), and the mantid response was noted. Each assay was conducted for 15 minutes unless the sawfly was 
consumed before this, at which point the assay was terminated. The predator response variables examined during the assay were number of attacks on sawfly, whether sawfly was discarded after mouth contact (SI 1a,b), and whether sawfly was consumed (SI 1c).

Discarding after mouth contact was a distinct behavior by the mantid, and could clearly be distinguished from the sawfly slipping or escaping from the mantid's grab. For individuals that were attacked multiple times, we noted discarding as yes if the individual was discarded after mouth contact even once.

Sawflies of all treatments were offered to all mantids but in different orders; six mantids received $A$. rosae in the order $\mathrm{C}+, \mathrm{AC}+, \mathrm{C}-$, seven in the order $\mathrm{C}-, \mathrm{C}+, \mathrm{AC}+$, and seven in the order $\mathrm{AC}+, \mathrm{C}-, \mathrm{C}+($ total number of replicates $\mathrm{N}=20$ ). Upon noticing the sawfly, the mantids would orient for an attack. However, we did not compare the latency until attack, because the position of the mantids and how readily they noticed the sawflies differed between replicates. Two mantids did not attack sawflies of any of the treatments during the assay and were thus excluded from analysis as these mantids afterwards molted. We did not examine the longterm survivorship of sawflies that were discarded after attack by mantids, but damage to the sawfly spanned the spectrum from none to lethal (SI 1a-c).

We expected mantids to attack $\mathrm{C}$ - sawflies but not $\mathrm{AC}+$ or $\mathrm{C}+$ sawflies, e.g., if there were any repellent olfactory cues associated with uptake of clerodanoids by the sawflies. If $\mathrm{AC}+$ or $\mathrm{C}+$ individuals were attacked, we expected the mantids to discard the sawflies after tasting deterrent compounds and thus not consume them.

\section{(c) Experiment 2: Microcosm experiment to investigate clerodanoid access effect on}

\section{survivorship in predator presence or absence}

We used a fully factorial design (clerodanoid access $\mathrm{x}$ mantid presence) to evaluate the effect of clerodanoid acquisition on sawfly survival in the presence of a mantid predator in a 
microcosm (figure $2 a$ ). The four treatments were C-sawfly without mantid (C-M-), C- sawfly with mantid $(\mathrm{C}-\mathrm{M}+), \mathrm{C}+$ sawfly without mantid $(\mathrm{C}+\mathrm{M}-)$ and $\mathrm{C}+$ sawfly with mantid $(\mathrm{C}+\mathrm{M}+)$ with a sample size of eleven, ten, ten, and eight, respectively. All trials were performed in microcosm cages (25 cm diameter, $26 \mathrm{~cm}$ height) with a honey-water supply. The cages were kept in a climate room at $20{ }^{\circ} \mathrm{C}(16 \mathrm{~h}: 8 \mathrm{~h}$ light: dark cycle, $70 \%$ relative humidity $)$ for the duration of the experiment. For each trial, we used five sawflies (three females and two males) and one or no mantid. We counted the number of sawflies alive every half-day for three days. For the mantid present trials, we also counted the number of sawflies 'dead but not consumed' at the end of three days, as sawflies may be attacked but not necessarily always completely consumed, e.g. if they are unpalatable. For these replicates, we calculated the number of consumed individuals as the difference between initial number of sawflies and the number of sawflies alive or 'dead but not consumed'. This experiment was conducted two weeks after experiment 1 and the mantids were fed a cricket diet in the meantime. We expected C- with mantids to have reduced survival than sawflies in the other treatments.

Moreover, we expected more $\mathrm{C}+$ sawflies to be consumed by the mantids with time, which could be either due to a decreasing concentration of the clerodanoids or to prolonged starvation of the mantids.

\section{(d) Experiment 3: Predation on $\mathrm{C}$ - conspecifics in mixed groups of $\mathrm{C}+$ and $\mathrm{C}$ - sawflies in}

\section{microcosm}

We aimed to test whether presence of $\mathrm{C}+$ sawflies led to defense against predation also for $\mathrm{C}$ sawflies. Therefore, we set up four group-composition treatments, consisting of varying relative abundance of $\mathrm{C}+$ and $\mathrm{C}$ - sawflies, keeping the total abundance of sawflies fixed at six. We chose six as the total abundance as we knew from experiment 2 that mantids can consume up to $5 \mathrm{C}$ - $A$. rosae adults over a period of 1-3 half-days. The first groupcomposition treatment consisted of six C-sawflies (6C-), and the other three mixed group- 
compositions treatments were: two $\mathrm{C}+$ and four $\mathrm{C}$ - sawflies $(2 \mathrm{C}+4 \mathrm{C}-)$, three $\mathrm{C}+$ and three $\mathrm{C}$ sawflies $(3 \mathrm{C}+3 \mathrm{C}-)$, and four $\mathrm{C}+$ and two $\mathrm{C}$ - sawflies $(4 \mathrm{C}+2 \mathrm{C}-)$. For each replicate, we joined the sawflies together in one petri dish according to the assigned group treatment two hours prior to adding them to the microcosm, to allow the sawflies to interact (e.g., mate or nibble).

We used eighteen mantids for the experiment, and a microcosm cage set-up identical to experiment 2. Each mantid was exposed to all group treatments in random order over multiple trials (four trials per mantid), with each trial lasting two days. Each mantid was fed a small cricket prior to each trial. For the mixed group-compositions treatments containing both $\mathrm{C}+$ and $\mathrm{C}$ - individuals, we used only females as $\mathrm{C}$ - and males as $\mathrm{C}+$. Using the different sexes allowed us to distinguish between $\mathrm{C}$ - and $\mathrm{C}+$ individuals in each replicate. From experiment 2, we know that both male and female sawflies are consumed by mantids (see Results). In A. rosae adults, males are usually smaller than females (Sawa et al., 1989; Travers-Martin \& Müller, 2008), making it potentially easier for C- females to nibble and gain access to clerodanoids from $\mathrm{C}+$ males. At the end of each trial, we counted the number of alive or 'dead but not consumed' $\mathrm{C}+$ and $\mathrm{C}$ - sawflies for each replicate. We calculated the number of consumed C-sawflies as the difference between initial number of $\mathrm{C}$ - sawflies and number of C- sawflies alive or 'dead but not consumed'. Similarly, we calculated the number of consumed $\mathrm{C}+$ sawflies. We hypothesized that the presence and increasing abundance of $\mathrm{C}+$ sawflies should lead to protection from predation for C- sawflies.

\section{(e) Chemical analysis of sawflies from experiment 3}

To test whether $\mathrm{C}$ - sawflies in mixed group-composition treatments acquired clerodanoids compared to 6C-replicates, we collected C-sawflies from different group-composition treatments and analysed them chemically. We also collected C+ sawflies to confirm their clerodanoid acquisition. Lastly, we examined if $\mathrm{C}+$ sawflies differed from $\mathrm{C}$ - sawflies of mixed group-composition treatment in the amount of clerodanoid acquired, i.e. if there is a 
difference between amount acquired directly from plant leaves or indirectly from conspecifics. We only collected individuals from replicates that had intact sawflies left at the end of the trial and stored them at $-80{ }^{\circ} \mathrm{C}$ until further analysis. The final sample size for $\mathrm{C}$ sawflies chemically analysed was six, five, seven, and five samples each of $6 \mathrm{C}-, 2 \mathrm{C}+4 \mathrm{C}-$, $3 \mathrm{C}+3 \mathrm{C}$ - and $4 \mathrm{C}+2 \mathrm{C}$ - group-composition treatments, respectively. The final sample size for $\mathrm{C}+$ sawflies was one, four and five from $2 \mathrm{C}+4 \mathrm{C}-, 3 \mathrm{C}+3 \mathrm{C}$ - and $4 \mathrm{C}+2 \mathrm{C}$ - group treatments, respectively. To extract putative clerodanoids from the sawflies, the individuals were freezedried and then homogenized using glass beads in a ball mill. Each individual was extracted twice by shaking for seven minutes at room temperature in ethyl acetate (LC-MS grade, VWR, Leuven, Belgium), and the supernatants were pooled to a final volume of $400 \mu 1$. The extracts were dried in a vacuum centrifuge at $35^{\circ} \mathrm{C}$. Dried extracts were suspended in $125 \mu 1$ $100 \%$ methanol (LC-MS grade, Fisher Scientific, Loughborough, UK) in an ultrasonic bath for 15 minutes, after which they were filtered using syringe filters (polytetrafluoroethylene membrane, $0.2 \mu \mathrm{m}$ pore size, Phenomenex, Torrance, CA, USA). The samples were analyzed using ultra high performance liquid chromatography (UHPLC; Dionex UltiMate 3000, Thermo Fisher Scientific, San José, CA, USA) with a Kinetex XB-C18 column $(1.7 \mu \mathrm{m}, 150$ $\times 2.1 \mathrm{~mm}$, with guard column, Phenomenex), and coupled to a quadrupole time of flight mass spectrometer (QTOF-MS; compact, Bruker Daltonics, Bremen, Germany), see SI 2 for details. The resulting chromatograms were processed with the software Compass Data Analysis 4.4 (Bruker Daltonics). The putative clerodanoids $482.22 \mathrm{~m} / \mathrm{z}\left(\mathrm{C}_{24} \mathrm{H}_{34} \mathrm{O}_{10}\right)$ and $484.23 \mathrm{~m} / \mathrm{z}\left(\mathrm{C}_{24} \mathrm{H}_{36} \mathrm{O}_{10}\right)$ occur in the chromatograms as $[\mathrm{M}+\mathrm{HCOOH}-\mathrm{H}]^{-}$adducts resulting in features with $527.21 \mathrm{~m} / \mathrm{z}$ and $529.23 \mathrm{~m} / \mathrm{z}$, respectively (Paul et al., 2021a). We manually integrated the peak areas of these two features from the extracted ion chromatograms, extracted with $0.02 \mathrm{~m} / \mathrm{z}$ accuracy. 
267 We expected C- sawflies from mixed group-composition treatments to acquire clerodanoids,

268 but to have lower amounts of clerodanoid compounds compared to $\mathrm{C}+$ sawflies.

\section{9 (f) Statistical analyses}

270 In experiment 1, we examined whether treatment had an effect on number of attacks, sawfly

271 being discarded after mouth contact, and sawfly being consumed using a binomial generalized

272 linear mixed-effects model (GLMM), with mantid identity as random effect. As there was

273 quasi-complete separation in our data for two variables (sawfly being discarded after mouth

274 contact and sawfly being consumed), i.e. the predictor variable could perfectly predict the

275 response variable for a subset of our data, we fitted a Bayesian binomial GLMM using 'blme'

276 package (version 1.0-5, Chung et al., 2013) for all variables. We evaluated if the order in

277 which the mantid was presented the treatments influenced the mantid response variables by

278 incorporating the trial round of a treatment as a fixed effect (due to only three levels) in each

279 model, and this gave qualitatively similar results (not shown).

280

281

282

283

In experiment 2, we examined the effect of treatment, time and their two-way interaction on

number of alive sawflies using a Poisson GLMM ('lme4' package version 1.1-27.1, Bates et

$a l ., 2015)$ with replicate ID as random effect. We also examined if there was a significant difference in number of consumed and 'dead but not consumed' sawflies between $\mathrm{C}$ - and C+ treatments with mantids $(\mathrm{C}-\mathrm{M}+$ and $\mathrm{C}+\mathrm{M}+)$ using a Kruskal-Wallis test.

In experiment 3, we calculated the proportion of consumed, alive and 'dead but not consumed' C- with respect to the initial abundance of C- sawflies in that replicate. We examined whether the proportion of consumed, alive, and 'dead but not consumed' Cindividuals differed significantly among the group-composition treatments using a binomial GLMM ('Ime4' package), with mantid identity and trial number as random effects. We considered the number of C- individuals consumed/alive/'dead but not consumed' as 
291

292

293

294

295

successes and initial number of C- present as the number of trials. Similarly, we calculated the proportion of consumed, alive, and 'dead but not consumed' $\mathrm{C}+$ with respect to the initial abundance of $\mathrm{C}+$ sawflies in that replicate. Finally, we examined if there was a significant difference in the amount (quantified based on peak area) of the two putative clerodanoid compounds between $\mathrm{C}$ - and $\mathrm{C}+$ sawflies of mixed group-composition treatments using a Kruskal-Wallis test.

All data was analyzed using R 4.0.5 (2021-03-31) (R Core Team, 2021). We checked and tested model assumptions statistically and visually. Posthoc-tests were conducted using 'multcomp' package (version 1.4-17, Hothorn et al., 2008).

\section{Results}

\section{(a) Experiment 1. Clerodanoid access protects against consumption by predator}

All sawflies irrespective of treatment were attacked at least once with no significant effect of treatment on number of attacks $\left(\chi^{2}=5.92\right.$, d.f. $=2, p=0.052$; figure $\left.1 b\right)$. In contrast, the treatments differed significantly in whether a sawfly was discarded after mouth contact by a mantid $\left(\chi^{2}=21.15\right.$, d.f. $=2, p<0.001$; figure $1 c$, SI 3a), with $\mathrm{C}+$ individuals dropped significantly more often compared to $\mathrm{C}$ - (posthoc test: $p<0.001)$ and $\mathrm{AC}+($ posthoc test: $p<$ 0.001). Likewise, treatment had a significant effect on whether an individual was consumed $\left(\chi^{2}=21.28\right.$, d.f. $=2, p<0.001$; figure $1 d$, SI $\left.3 b\right)$, with $\mathrm{C}+$ individuals $(0 \%$ consumed $)$ being significantly less likely to be consumed compared to C- (100\% consumed) (posthoc test: $p<$ $0.001)$ and $\mathrm{AC}+(70 \%$ consumed $)$ (posthoc test: $p=0.001)$.

\section{(b) Experiment 2. C+ individuals are not consumed by predator even after prolonged}

\section{exposure}

There was a significant interactive effect of treatment and time on number of sawflies alive $\left(\chi^{2}=36.76\right.$, d.f. $\left.=3, p<0.001\right)$. In the treatment with no mantids, all $\mathrm{C}$ - and all but one $\mathrm{C}+$ 
315 individual survived across all replicates (figure $2 b$ ). In C- treatments with mantids, no

316 individual was alive after three-half days. In contrast, for $\mathrm{C}+$ treatments with mantids, all

317 individuals were alive in two replicates. In the other six $\mathrm{C}+\mathrm{M}+$ replicates the number of alive

318 individuals decreased with time, although in no replicate all individuals were killed. There

319 was a significant difference in number of consumed sawflies $\left(\chi^{2}=15.63\right.$, d.f. $=1, p<0.001$,

320 figure $2 c$ ) with all sawflies consumed in the $\mathrm{C}-\mathrm{M}+$ treatment, while only few sawflies were

321 consumed across three replicates in the $\mathrm{C}+\mathrm{M}+$ treatment. Similarly, the number of 'dead but

322 not consumed' individuals significantly differed between $\mathrm{C}-\mathrm{M}+$ and $\mathrm{C}+\mathrm{M}+$ treatments $\left(\chi^{2}=\right.$

3235.95 , d.f. $=1, p=0.014$, figure $2 d$ ). In four $\mathrm{C}+$ replicates but zero C- replicates, we collected

324 'dead but not consumed' individuals, suggesting that while the mantids attacked C+

325 individuals, they were not always consumed.

326 (c) Experiment 3. Less $\mathrm{C}$ - individuals consumed by predator, if $\mathrm{C}+$ individuals are

327 present

328 Group-composition treatment had a significant effect on the proportion of consumed C-

329 sawflies $\left(\chi^{2}=41.87\right.$, d.f. $=3, p<0.001$; figure $\left.3 a\right)$, with significantly more C- consumed in

330 the $6 \mathrm{C}$ - treatment compared to the $2 \mathrm{C}+4 \mathrm{C}$ - (posthoc test: $p<0.001$ ), $3 \mathrm{C}+3 \mathrm{C}$ - (posthoc test: $p$

$331<0.001$ ), and 4C+2C- (posthoc test: $p<0.001$ ) treatments. There was no significant

332 difference between the other treatments (SI 4a). The proportion of alive $\mathrm{C}$ - sawflies differed

333 between the treatments $\left(\chi^{2}=27.23\right.$, d.f. $=3, p<0.001$; figure $\left.3 b\right)$, with significantly less C-

334 alive in the $6 \mathrm{C}$ - compared to the $2 \mathrm{C}+4 \mathrm{C}$ - (posthoc test: $p=0.005$ ) and $3 \mathrm{C}+3 \mathrm{C}$ - (posthoc test:

$335 p<0.001)$ treatment, while other treatments were not significantly different (SI $4 b)$.

336 Similarly, the proportion of 'dead but not consumed' C- sawflies differed between the

337 treatments $\left(\chi^{2}=8.77\right.$, d.f. $=3, p=0.032$; figure $3 c$ ), with significantly more C- sawflies being

338 'dead but not consumed' in the $4 \mathrm{C}+2 \mathrm{C}$ - compared to the $6 \mathrm{C}$ - treatment (posthoc test: $p=$

339 0.029), and no other significant differences between treatments (SI 4c). Similarly, to 
experiment 2, C+ sawflies were consumed rarely, although in many replicates there were

'dead but not consumed' C+ individuals (SI 5a-c).

342

The chemical analysis revealed that the putative clerodanoids $482.22 \mathrm{~m} / \mathrm{z}$ and $484.23 \mathrm{~m} / \mathrm{z}$ could be detected in sixteen $(\sim 94 \%)$ and fourteen $(\sim 82 \%)$, respectively, of the seventeen sampled C- sawflies from mixed group-composition treatments (figure $4 a, b)$. All ten (100\%)

$\mathrm{C}+$ sawflies had acquired both putative clerodanoids (figure 4). There was intraspecific variation in the amount of clerodanoids acquired for both $\mathrm{C}+$ and $\mathrm{C}$ - sawflies of mixed groups. Two out of six replicates of the 6C-group-treatment also had small amounts of clerodanoids (figure 4), possibly resulting from contamination as these replicates were placed in the microcosms where previously mixed group-composition treatments were housed. This contamination could also potentially explain why these C- sawflies were not consumed by the mantids. $\mathrm{C}+$ sawflies had significantly higher amounts of both clerodanoids, $482.22 \mathrm{~m} / \mathrm{z}\left(\chi^{2}=\right.$ 10.98 , d.f. $=1, p<0.001$, figure $4 a)$ and $484.23 \mathrm{~m} / \mathrm{z}\left(\chi^{2}=15.75\right.$, d.f. $=1, p<0.001$, figure 4b), than C-sawflies for mixed group-composition treatments.

\section{Discussion}

Chemical defense as an anti-predator strategy is widespread and well-documented in animals (Speed et al., 2012). However, it is less clear if such chemical defense can be intraspecifically transmitted and whether presence of chemically defended individuals can confer protection onto undefended conspecifics. In some species, such defensive chemicals can be taken up independently of the nutrient-delivering food source, as in the case of our study organism, A. rosae, that takes up clerodanoids (and potentially also other chemicals) pharmacophagously from $A$. reptans plants and likely metabolized them (Paul et al., 2021b). Here, we showed that direct access to A. reptans leaves serves as defense against predation by making the sawflies unpalatable to the predator. We also demonstrated that clerodanoid 
364 access provides protection not only to focal individuals but also to conspecifics in mixed

365 groups of $\mathrm{C}+$ and $\mathrm{C}$ - individuals.

366 While most sawflies without access to clerodanoids were lethally attacked and consumed by

367 the mantids, only very few sawflies that had taken up clerodanoids from leaves were

368 consumed, as we had predicted. Nevertheless, many sawflies with clerodanoid access were

369 also attacked but then readily rejected by the mantids, as shown by the 'discarding after

370 mouth contact' behavior in experiment 1 and by the higher number of 'dead but not

371 consumed' sawflies in experiment 2. This rejection is likely induced by the bitter taste of the

372 clerodanoids that may be deposited on the cuticle and in body tissue of the adult sawfly

373 (Nishida \& Fukami, 1990). When tested directly, two clerodanoids (clerodendrin B and D)

374 had a deterrent effect on Japanese tree sparrows, who consumed fewer rice grains that had

375 been treated with the clerodanoids compared to untreated grains (Nishida \& Fukami, 1990). A

376 taste-rejection behavior, in which predators taste but do not ingest a prey item, as found by

377 the mantids in the present experiment, has been shown to be elicited by distasteful prey and

378 can lead to an increased survivorship of the prey (Halpin \& Rowe, 2017). Although we did

379 not quantify the long term survivorship of sawflies after mantid attack in experiment 1 , visual

380 inspection showed that the damage spectrum ranged from nearly unharmed to dead sawflies

381 (SI 1a,b), indicating that clerodanoid uptake could lead to survivorship advantages.

382 Adult $A$. rosae can acquire clerodanoids not only from plants but also from conspecifics via

383 nibbling on their body surface. However, acquiring clerodanoids indirectly from conspecifics

384 resulted in less protection than direct acquisition from the plants in $A$. rosae in our

385 experiments. Not all sawflies successfully acquire sufficient clerodanoid amounts from C +

386 conspecifics (Paul et al., 2021a) and the concentrations could be much lower than after direct

387 uptake from the $A$. reptans leaves (figure 4). Such quantitative and potentially also qualitative

388 differences in clerodanoid acquisition may explain, why many AC+ sawflies (experiment 1) 
and $\mathrm{C}$ - sawflies in mixed $\mathrm{C}+\mathrm{C}$ - group treatments (experiment 3 ) were consumed by mantids.

The effectiveness of defense chemicals sequestered from host plants against predators has been shown to be concentration-dependent in a glucosinolate-sequestering leaf beetle species, with individuals having lower levels of sequestered glucosinolates being more susceptible to predation (Sporer et al., 2020). In A. rosae, transfer of clerodanoids can occur both within and between sexes (Paul et al., 2021a), which seems rather exceptional. In other insect species, usually chemicals are transferred from the male to the female during mating. For example, in some arctiid moth species, pyrrolizidine alkaloids are sexually transmitted from males to females, and these chemicals render protection against predation to the recipient female (Gonzalez et al., 1999; Conner et al., 2000). Moreover, such defensive chemicals acquired by the female from the male can also be incorporated into the offspring (Eisner et al., 2002; Camarano et al., 2009; Sternberg et al., 2015) providing it with benefits. Evidence for such benefits of parental clerodanoid access to offspring in A. rosae is currently lacking (Paul et al., 2021b).

Our data from the predation microcosm experiment (experiment 2) demonstrated that the mantids attacked $\mathrm{C}+$ sawflies, with number of alive sawflies decreasing over time, but this decline was less rapid than that of $\mathrm{C}$ - sawflies in presence of mantids. This suggests that the mantids may learn to avoid $\mathrm{C}+$ sawflies after first encounters, leading to a longer survival period of the sawflies. Learned aversion has been found in the mantid Tenodera aridifolia, where the mantids reduced attacks on certain prey items when these prey items were made bitter (Carle et al., 2018). Similarly, repeated exposure to unpalatable milkweed bugs that had sequestered cardenolides from their host plants led to avoidance by T. aridifolia of both palatable and unpalatable milkweed bugs altogether (Berenbaum \& Miliczky, 1984). Interestingly, the mantid $H$. patellifera attacked sawflies in both experiment 2 and 3 despite having been exposed to the $\mathrm{C}+$ sawflies previously, suggesting that such avoidance learning 
may not last long, as also seen in T. aridifolia (Prudic et al., 2007). Moreover, such avoidance

415 learning can be more effective if the distasteful prey is conspicuously colored (Roper \&

416 Redston, 1987; Raška et al., 2017). Indeed, organisms that use chemical defenses are usually,

417 but not always, brightly colored and conspicuous, i.e. aposematic, to advertise their facilitate temporary avoidance learning by mantids.

In line with our prediction, the presence of $\mathrm{C}+$ sawflies was beneficial for $\mathrm{C}$ - sawflies with a prey items) increased, but birds only discriminated between the models and mimics when the frequency of mimics was above 25\% (Skelhorn \& Rowe, 2007). Moreover, density- 
439 informational state of the predator, leading to state-dependent decision-making (Aubier \&

440 Sherratt, 2020).

441 In natural populations of $A$. rosae, intraspecific variation in clerodanoid uptake could be

442 expected if the distribution of pharmacophagy-suitable plants is patchy, if there in

443 intraspecific variation in the clerodanoid concentrations available from the plants, or if there

444 are associated costs of clerodanoid uptake. Indeed, A. rosae individuals that were exposed to

445 clerodanoids had a shorter lifespan than control individuals (Zanchi et al., 2021). This

446 suggests that there might be costs to clerodanoid uptake, although clerodanoid access did not

447 immediately cause high mortality during our observed period in experiment 2 (figure $2 b$ ).

448 Similar costs of chemical defense have been revealed in swallowtail butterflies of the tribe

449 Troidini which showed reduced larval survivorship (Dimarco \& Fordyce, 2017) or a reduction

450 in adult fat content (Fordyce \& Nice, 2008) when sequestering toxic alkaloids. Our study

451 demonstrates that even if individuals do not take up clerodanoids, they could still benefit

452 indirectly from conspecifics that do. This could lead to emergence of cheaters that do not pay

453 the cost of chemical defense but enjoy the benefits (Lindstedt et al., 2018). Future studies

454 should examine variation in clerodanoid contents in natural populations of $A$. rosae. In

455 conclusion, our study showed that clerodanoids serve as chemical defense for $A$. rosae that

456 can be intraspecifically transferred. Furthermore, chemically defended sawflies can confer

457 protection onto conspecifics that had no direct access to clerodanoids in a group, indicating a

458 'herd-protection' effect.

\section{References}


Arias, M., Meichanetzoglou, A., Elias, M., Rosser, N., Silva, D.L. de-, Nay, B., et al. (2016) Variation in cyanogenic compounds concentration within a Heliconius butterfly community: does mimicry explain everything? BMC Evolutionary Biology, 16, 272.

Aubier, T.G., Joron, M. \& Sherratt, T.N. (2017) Mimicry among unequally defended prey should be mutualistic when predators sample optimally. The American Naturalist, 189, 267-282.

Aubier, T.G. \& Sherratt, T.N. (2020) State-dependent decision-making by predators and its consequences for mimicry. The American Naturalist, 196, E127-E144.

Bates, D., Mächler, M., Bolker, B. \& Walker, S. (2015) Fitting linear mixed-effects models using Ime4. Journal of Statistical Software, 67, 1-48.

Berenbaum, M.R. \& Miliczky, E. (1984) Mantids and milkweed bugs: efficacy of aposematic coloration against invertebrate predators. American Midland Naturalist, 111, 64.

Bergen, E. \& Beldade, P. (2019) Seasonal plasticity in anti-predatory strategies: Matching of color and color preference for effective crypsis. Evolution Letters, 3, 313-320.

Best, R., Ruxton, G.D. \& Gardner, A. (2018) Intragroup and intragenomic conflict over chemical defense against predators. Ecology and Evolution, 8, 3322-3329.

Boevé, J.-L. \& Müller, C. (2005) Defence effectiveness of easy bleeding sawfly larvae towards invertebrate and avian predators. Chemoecology, 15, 51-58.

Boppré, M. (1984) Redefining "pharmacophagy." Journal of Chemical Ecology, 10, 1151-1154.

Brower, L.P., Pough, F.H. \& Meck, H. (1970) Theoretical investigations of automimicry, I. Single trial learning. Proceedings of the National Academy of Sciences, 66, 1059-1066.

Camarano, S., González, A. \& Rossini, C. (2009) Biparental endowment of endogenous defensive alkaloids in Epilachna paenulata. Journal of Chemical Ecology, 35, 1-7.

Carle, T., Horiwaki, R., Hurlbert, A. \& Yamawaki, Y. (2018) Aversive learning in the praying mantis (Tenodera aridifolia), a sit and wait predator. Journal of Insect Behavior, 31, 158-175.

Castro, É.C.P. de, Musgrove, J., Bak, S., McMillan, W.O. \& Jiggins, C.D. (2021) Phenotypic plasticity in chemical defence of butterflies allows usage of diverse host plants. Biology Letters, 17, rsbl.2020.0863, 20200863.

Chouteau, M., Arias, M. \& Joron, M. (2016) Warning signals are under positive frequency-dependent selection in nature. Proceedings of the National Academy of Sciences, 113, 2164-2169.

Chung, Y., Rabe-Hesketh, S., Dorie, V., Gelman, A. \& Liu, J. (2013) A nondegenerate penalized likelihood estimator for variance parameters in multilevel models. Psychometrika, 78, 685709.

Conner, W.E., Boada, R., Schroeder, F.C., Gonzalez, A., Meinwald, J. \& Eisner, T. (2000) Chemical defense: Bestowal of a nuptial alkaloidal garment by a male moth on its mate. Proceedings of the National Academy of Sciences, 97, 14406-14411.

Cyriac, V.P. \& Kodandaramaiah, U. (2019) Don't waste your time: predators avoid prey with conspicuous colors that signal long handling time. Evolutionary Ecology, 33, 625-636.

Dimarco, R.D. \& Fordyce, J.A. (2017) Not all toxic butterflies are toxic: high intra- and interspecific variation in sequestration in subtropical swallowtails. Ecosphere, $\mathbf{8}$.

Edmunds, M. (1974) Defence in animals: a survey of anti-predator defences. Longman Publishing Group.

Eisner, T., Eisner, M., Siegler, M., et al. (2005) Secret weapons: defenses of insects, spiders, scorpions, and other many-legged creatures. Harvard University Press.

Eisner, T., Rossini, C., González, A., Iyengar, V.K., Siegler, M.V. \& Smedley, S.R. (2002) Paternal investment in egg defence. In Chemoecology of insect eggs and egg deposition. Blackwell Publishing Oxford, pp. 91-116.

Erb, M. \& Robert, C.A. (2016) Sequestration of plant secondary metabolites by insect herbivores: molecular mechanisms and ecological consequences. Current Opinion in Insect Science, 14, 8-11.

Finkbeiner, S.D., Salazar, P.A., Nogales, S., Rush, C.E., Briscoe, A.D., Hill, R.I., et al. (2018) Frequency dependence shapes the adaptive landscape of imperfect Batesian mimicry. Proceedings of the Royal Society B: Biological Sciences, 285, 20172786. 
Fordyce, J.A. \& Nice, C.C. (2008) Antagonistic, stage-specific selection on defensive chemical sequestration in a toxic butterfly. Evolution, 62, 1610-1617.

Gamberale-Stille, G. \& Guilford, T. (2004) Automimicry destabilizes aposematism: predator sampleand-reject behaviour may provide a solution. Proceedings of the Royal Society of London. Series B: Biological Sciences, 271, 2621-2625.

González, A., Rossini, C., Eisner, M. \& Eisner, T. (1999) Sexually transmitted chemical defense in a moth (Utetheisa ornatrix). Proceedings of the National Academy of Sciences, 96, 5570-5574.

Halpin, C.G. \& Rowe, C. (2016) The effect of distastefulness and conspicuous coloration on the postattack rejection behaviour of predators and survival of prey. Biological Journal of the Linnean Society.

Hämäläinen, L., Mappes, J., Rowland, H.M., Teichmann, M. \& Thorogood, R. (2020) Social learning within and across predator species reduces attacks on novel aposematic prey. Journal of Animal Ecology, 89, 1153-1164.

Hashimoto, K. \& Hayashi, F. (2014) Cantharidin world in nature: a concealed arthropod assemblage with interactions via the terpenoid cantharidin: Arthropods interacted via cantharidin. Entomological Science, 17, 388-395.

Hothorn, T., Bretz, F. \& Westfall, P. (2008) Simultaneous inference in general parametric models. Biometrical Journal, 50, 346-363.

Kawai, K., Amano, T., Nishida, R., Kuwahara, Y. \& Fukami, H. (1998) Clerodendrins from Clerodendron trichotomum and their feeding stimulant activity for the turnip sawfly. Phytochemistry, 49, 1975-1980.

Kikuchi, D.W., Herberstein, M.E., Barfield, M., Holt, R.D. \& Mappes, J. (2021) Why aren't warning signals everywhere? On the prevalence of aposematism and mimicry in communities. Biological Reviews, 96, 2446-2460.

Lawson, N., Vane-Wright, R.I. \& Boppré, M. (2021) The puzzle of monarch butterflies ( Danaus plexippus ) and their association with plants containing pyrrolizidine alkaloids. Ecological Entomology, 46, 999-1005.

Lindstedt, C., Miettinen, A., Freitak, D., Ketola, T., López-Sepulcre, A., Mäntylä, E., et al. (2018) Ecological conditions alter cooperative behaviour and its costs in a chemically defended sawfly. Proceedings of the Royal Society B: Biological Sciences, 285, 20180466.

Matsubara, S. \& Sugiura, S. (2017) Chemical defence of turnip sawfly larvae against Japanese tree frogs. Journal of Asia-Pacific Entomology, 20, 225-227.

Mattila, A.L.K., Jiggins, C.D., Opedal, Ø.H., Montejo-Kovacevich, G., Pinheiro de castro, É.C., McMillan, W.O., et al. (2021) Evolutionary and ecological processes influencing chemical defense variation in an aposematic and mimetic Heliconius butterfly. PeerJ, 9, e11523.

Matz, C., Webb, J.S., Schupp, P.J., Phang, S.Y., Penesyan, A., Egan, S., et al. (2008) Marine biofilm bacteria evade eukaryotic predation by targeted chemical defense. PLOS ONE, 3, e2744.

Müller, C. \& Arand, K. (2007) Trade-offs in oviposition choice? Food-dependent performance and defence against predators of a herbivorous sawfly. Entomologia Experimentalis et Applicata, 124, 153-159.

Müller, C. \& Brakefield, P.M. (2003) Analysis of a chemical defense in sawfly larvae: Easy bleeding targets predatory wasps in late summer. Journal of Chemical Ecology, 29, 2683-2694.

Müller, C. \& Sieling, N. (2006) Effects of glucosinolate and myrosinase levels in Brassica juncea on a glucosinolate-sequestering herbivore - and vice versa. Chemoecology, 16, 191-201.

Nishida, R. (2014) Chemical ecology of insect-plant interactions: ecological significance of plant secondary metabolites. Bioscience, Biotechnology, and Biochemistry, 78, 1-13.

Nishida, R. \& Fukami, H. (1990) Sequestration of distasteful compounds by some pharmacophagous insects. Journal of Chemical Ecology, 16, 151-164.

Opitz, S.E.W., Jensen, S.R. \& Müller, C. (2010) Sequestration of glucosinolates and iridoid glucosides in sawfly species of the genus Athalia and their role in defense against ants. Journal of Chemical Ecology, 36, 148-157. 
Opitz, S.E.W. \& Müller, C. (2009) Plant chemistry and insect sequestration. Chemoecology, 19, 117154.

Pančić, M. \& Kiørboe, T. (2018) Phytoplankton defence mechanisms: traits and trade-offs. Biological Reviews, 93, 1269-1303.

Paul, S.C., Dennis, A.B., Tewes, L.J., Friedrichs, J. \& Müller, C. (2021a) Consequences of pharmacophagous uptake from plants and conspecifics in a sawfly elucidated using chemical and molecular techniques (preprint). BioRxiv (doi: 10.1101/2021.02.09.430406).

Paul, S.C. \& Müller, C. (2021) Fighting over defence chemicals disrupts mating behaviour. In press. Behavioral Ecology.

Paul, S.C., Singh, P., Dennis, A.B. \& Müller, C. (2021b) Intergenerational Effects of Early Life Starvation on Life-History, Consumption, and Transcriptome of a Holometabolous Insect. In press. The American Naturalist.

Poulton, E.B. (1890) The colours of animals: their meaning and use, especially considered in the case of insects. D. Appleton.

Prudic, K.L., Skemp, A.K. \& Papaj, D.R. (2007) Aposematic coloration, luminance contrast, and the benefits of conspicuousness. Behavioral Ecology, 18, 41-46.

Prudic, K.L., Timmermann, B.N., Papaj, D.R., Ritland, D.B. \& Oliver, J.C. (2019) Mimicry in viceroy butterflies is dependent on abundance of the model queen butterfly. Communications Biology, 2, 68.

R Core Team. (2021) R: A Language and Environment for Statistical Computing. R Foundation for Statistical Computing, Vienna, Austria.

Raška, J., Štys, P. \& Exnerová, A. (2017) How variation in prey aposematic signals affects avoidance learning, generalization and memory of a salticid spider. Animal Behaviour, 130, 107-117.

Roper, T.J. \& Redston, S. (1987) Conspicuousness of distasteful prey affects the strength and durability of one-trial avoidance learning. Animal Behaviour, 35, 739-747.

Rowland, H.M., Burriss, R.P. \& Skelhorn, J. (2020) The antipredator benefits of postural camouflage in peppered moth caterpillars. Scientific Reports, 10, 21654.

Santos, J.C., Tarvin, R.D. \& O'Connell, L.A. (2016) A review of chemical defense in poison Frogs (Dendrobatidae): Ecology, pharmacokinetics, and autoresistance. In Chemical Signals in Vertebrates 13 (ed. by Schulte, B.A., Goodwin, T.E. \& Ferkin, M.H.). Springer International Publishing, Cham, pp. 305-337.

Sawa, M., Fukunaga, A., Naito, T., Oishi, K., \& others. (1989) Studies on the sawfly, Athalia rosae (Insecta, Hymenoptera, Tenthredinidae). I. General biology. Zoological Science, 6, 541-547.

Sculfort, O., Castro, E.C.P., Kozak, K.M., Bak, S., Elias, M., Nay, B., et al. (2020) Variation of chemical compounds in wild Heliconiini reveals ecological factors involved in the evolution of chemical defenses in mimetic butterflies. Ecology and Evolution, 10, 2677-2694.

Skelhorn, J. \& Rowe, C. (2007) Automimic frequency influences the foraging decisions of avian predators on aposematic prey. Animal Behaviour, 74, 1563-1572.

Skelhorn, J., Rowland, H.M., Delf, J., Speed, M.P. \& Ruxton, G.D. (2011) Density-dependent predation influences the evolution and behavior of masquerading prey. Proceedings of the National Academy of Sciences, 108, 6532-6536.

Smilanich, A.M., Dyer, L.A., Chambers, J.Q. \& Bowers, M.D. (2009) Immunological cost of chemical defence and the evolution of herbivore diet breadth. Ecology Letters, 12, 612-621.

Speed, M.P., Ruxton, G.D., Mappes, J. \& Sherratt, T.N. (2012) Why are defensive toxins so variable? An evolutionary perspective. Biological Reviews, 87, 874-884.

Speed, M.P. \& Turner, J.R.G. (1999) Learning and memory in mimicry: II. Do we understand the mimicry spectrum? Biological Journal of the Linnean Society, 67, 281-312.

Sporer, T., Körnig, J. \& Beran, F. (2020) Ontogenetic differences in the chemical defence of flea beetles influence their predation risk. Functional Ecology, 34, 1370-1379.

Sternberg, E.D., Roode, J.C. de \& Hunter, M.D. (2015) Trans-generational parasite protection associated with paternal diet. Journal of Animal Ecology, 84, 310-321.

Sugiura, S. (2020) Predators as drivers of insect defenses. Entomological Science, 23, 316-337. 
Tea, Y., Soong, J.W., Beaver, E.P. \& Lohman, D.J. (2021) Kleptopharmacophagy: Milkweed butterflies scratch and imbibe from Apocynaceae-feeding caterpillars. Ecology. preference of a specialist herbivore. Functional Ecology, 22, 1033-1043.

Tuttle, L.J., Lamb, R.W. \& Stringer, A.L. (2021) Differential learning by native versus invasive predators to avoid distasteful cleaning mutualists. Functional Ecology, 35, 1481-1490.

Vlieger, L., Brakefield, P.M. \& Müller, C. (2004) Effectiveness of the defence mechanism of the turnip sawfly, Athalia rosae (Hymenoptera: Tenthredinidae), against predation by lizards. Bulletin of Entomological Research, 94, 283-289.

Zanchi, C., Lo, L.K., R, R., Moritz, I., Kurtz, J. \& Müller, C. (2021) Survival of the sawfly Athalia rosae upon infection by an entomopathogenic fungus and in relation to clerodanoid uptake. Frontiers in Physiology, 12, 637617.

Züst, T., Mou, S. \& Agrawal, A.A. (2018) What doesn't kill you makes you stronger: The burdens and benefits of toxin sequestration in a milkweed aphid. Functional Ecology, 32, 1972-1981.

Zvereva, E.L. \& Kozlov, M.V. (2015) The costs and effectiveness of chemical defenses in herbivorous insects: a meta-analysis. Ecological Monographs, 15-0911.1. 
Figures

A

637

638

639

640

641

642

643

644

645

646
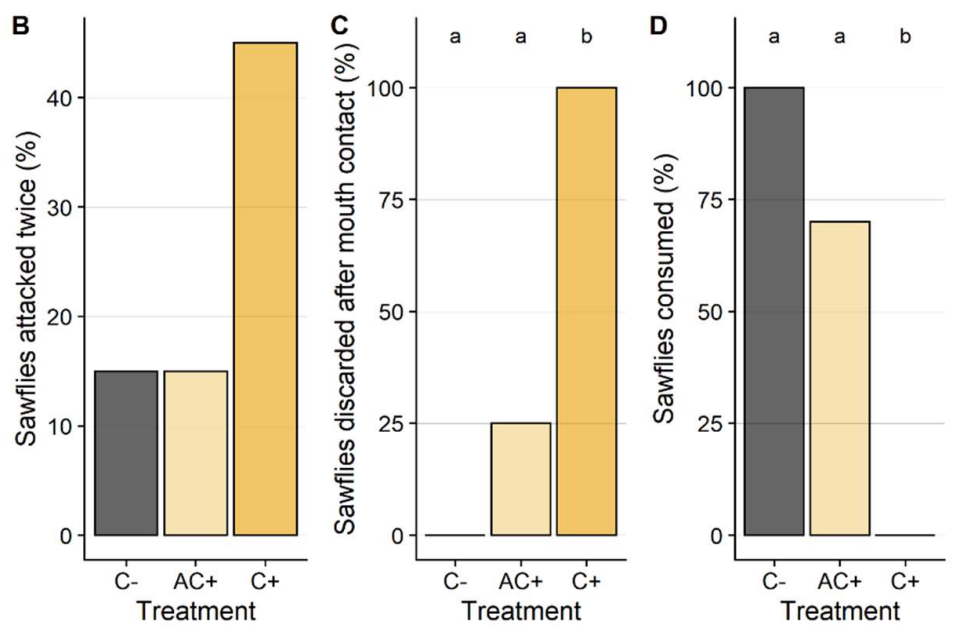

Figure 1. (A) Experimental design illustration of no-choice feeding assay, where each mantid

was exposed to one Athalia rosae sawfly of different clerodanoid treatments (C- no access,

$\mathrm{AC}+$ indirect access via conspecific that had contact with leaf of Ajuga reptans, $\mathrm{C}+$ direct

access to A. reptans) over multiple trials performed in different orders. Effects of clerodanoid

treatment on percentage of sawflies that were (B) attacked twice (all other sawflies were

attacked once), (C) discarded after mouth contact, and (D) consumed, by mantid ( $n=20$

replicates per treatment). Different letters denote significantly different treatment effects

inferred from Tukey HSD post hoc tests. 
A
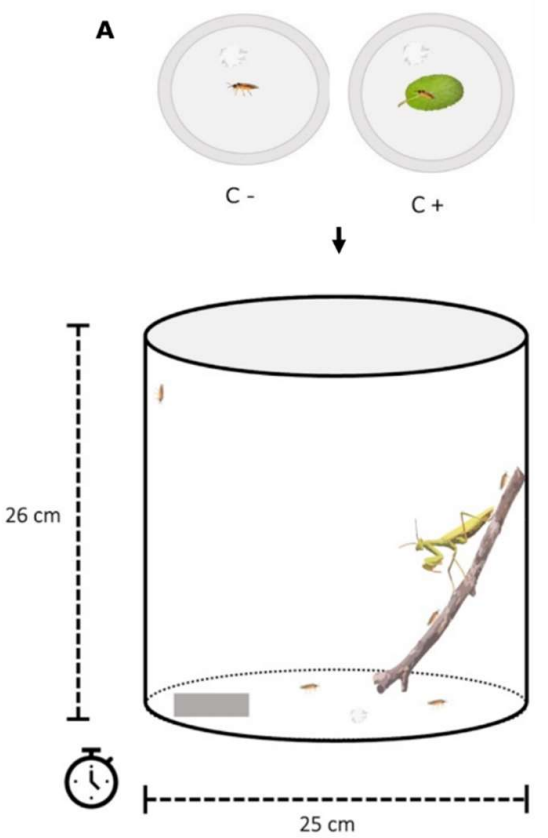

B

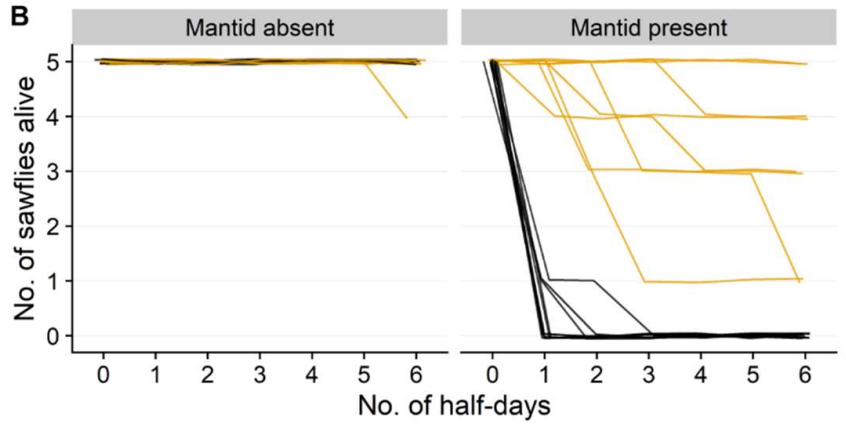

Sawfly.clerodanoid.treatment $-\mathrm{C}--\mathrm{C}+$

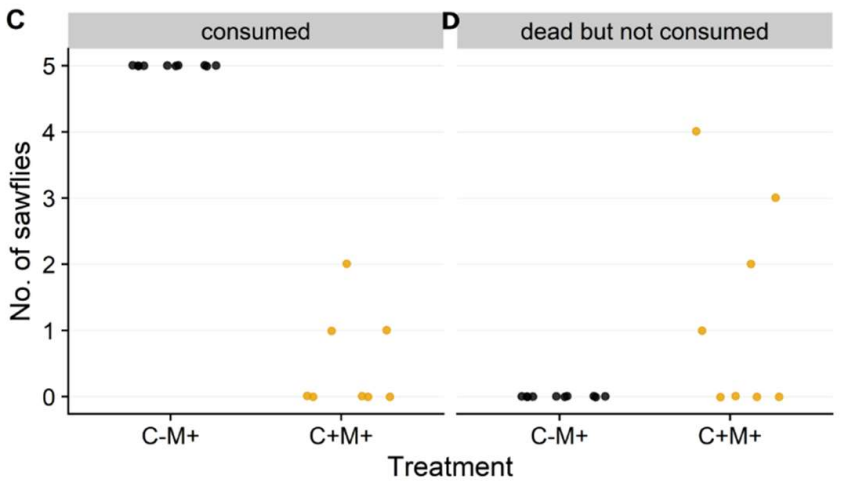

648 Figure 2. (A) Experimental design illustration of clerodanoid treatment (C- no access, C+

649 access to leaf of Ajuga reptans) and predation microcosm experiment, where in each

650 microcosm five Athalia rosae sawflies were added that were either C- or C+ and with-or-

651 without a mantid. B) Number of alive sawflies of different clerodanoid treatments over time.

652 Lines are jittered to decrease overlapping. Number of $\mathrm{C}$ - and $\mathrm{C}+$ individuals that were $(\mathrm{C})$ consumed or (D) 'dead but not consumed' in replicates of mantid present $(\mathrm{M}+)$ treatment. 

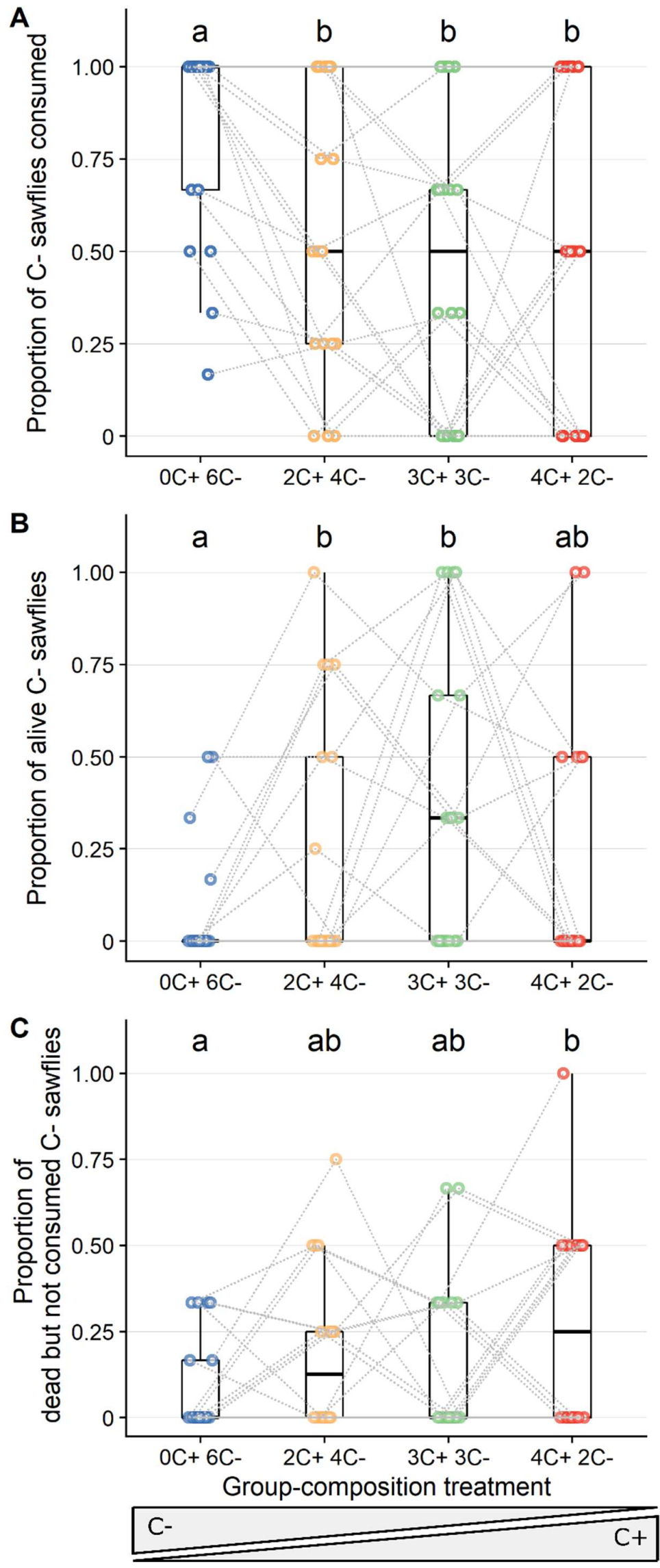
656 Figure 3. Effects of different group-composition, i.e. varying relative abundance of Athalia

657 rosae sawflies with $(\mathrm{C}+)$ and without $(\mathrm{C}-)$ access to a leaf of Ajuga reptans and thus

658 clerodanoids, on proportions of (A) consumed, (B) alive, and (C) 'dead but not consumed' C-

659 sawflies in presence of a mantid. Data are presented as boxplots, medians and interquartile

660 with individual data points also plotted. Grey dotted lines connect data from each mantid $(n=$

661 18) across trials. Note that abundance of C- sawflies decreases and C+ increases from left to

662 right. 

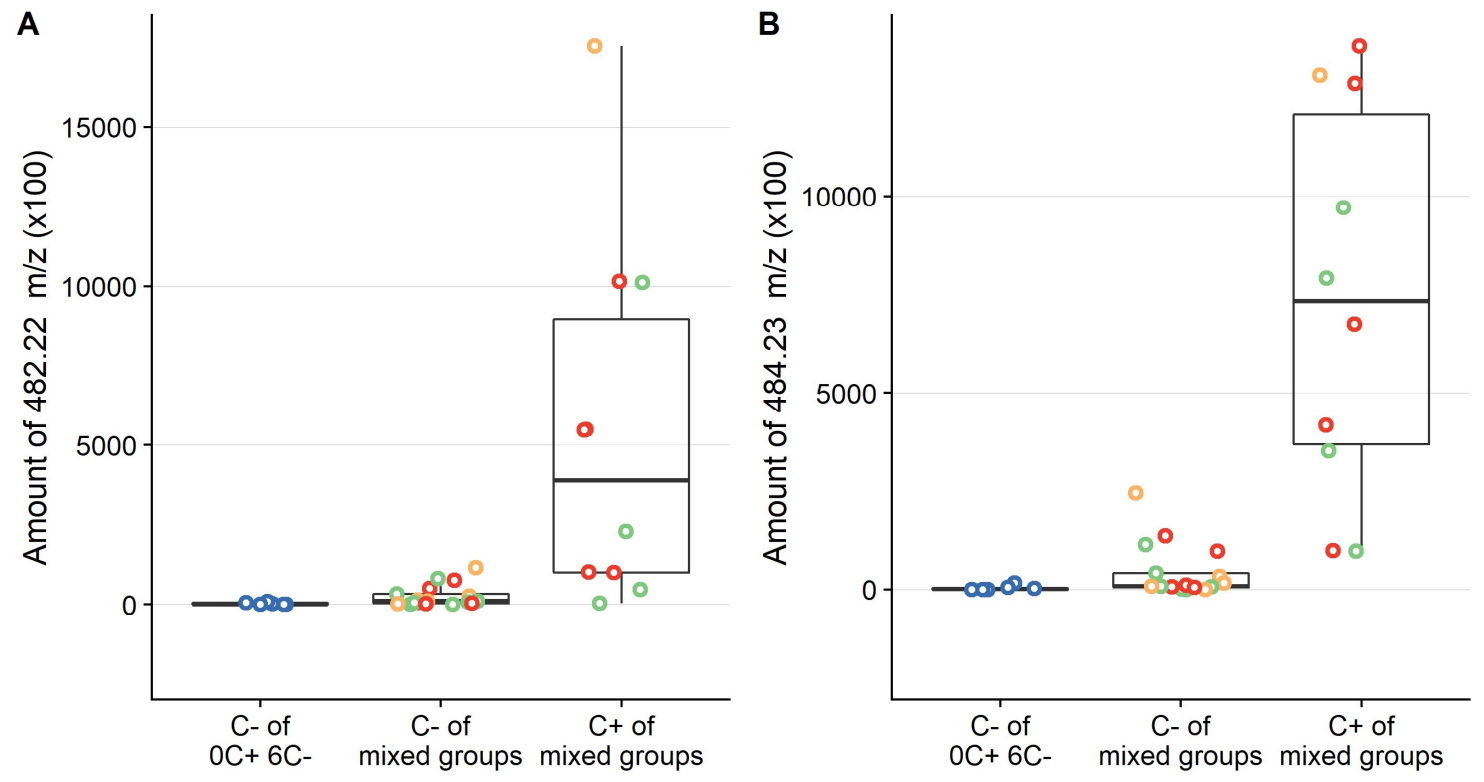

Group-composition treatment $\circ 0 \mathrm{C}+6 \mathrm{C}-\circ 2 \mathrm{C}+4 \mathrm{C}-\circ 3 \mathrm{C}+3 \mathrm{C}-\quad \circ 4 \mathrm{C}+2 \mathrm{C}-$

664 Figure 4. Amount (peak area) of candidate chemical features representing putative

665 clerodanoids, (A) $482.22 \mathrm{~m} / \mathrm{z}\left(\mathrm{C}_{24} \mathrm{H}_{34} \mathrm{O}_{10}\right)$ and (B) $484.23 \mathrm{~m} / \mathrm{z}\left(\mathrm{C}_{24} \mathrm{H}_{36} \mathrm{O}_{10}\right)$, respectively, from

666 the extracted ion chromatograms for C- (without access to a leaf of Ajuga reptans) and C+

667 (with access to a leaf of $A$. reptans) sawflies of different group-composition treatments.

668 Mixed groups represent groups that had both $\mathrm{C}+$ and $\mathrm{C}$ - sawflies present in the microcosm,

669 while $0 \mathrm{C}+6 \mathrm{C}$ - had only C- sawflies present. 